\title{
HIV-1 downregulates the expression and phosphorylation of receptor tyrosine kinase by targeting the NF- $\mathrm{NB}$ pathway
}

\author{
TINGTING FENG ${ }^{1}$, JIANHE GAN ${ }^{1}$, AILAN QIN ${ }^{1}$, XIAOPING HUANG ${ }^{1}$, \\ NANPING WU ${ }^{2}, \mathrm{HUA} \mathrm{HU}^{3}$ and HANGPING $\mathrm{YAO}^{2}$ \\ ${ }^{1}$ Department of Infectious Disease, The First Affiliated Hospital of Soochow University, Suzhou, Jiangsu 215006; \\ ${ }^{2}$ State Key Laboratory for Diagnosis and Treatment of Infectious Diseases, First Affiliated Hospital, \\ Zhejiang University School of Medicine, Hangzhou, Zhejiang 310003; ${ }^{3}$ Department of Neurology, \\ The Second Affiliated Hospital of Soochow University, Suzhou, Jiangsu 215006, P.R. China
}

Received July 28, 2015; Accepted June 24, 2016

DOI: $10.3892 / \mathrm{mmr} .2016 .5487$

\begin{abstract}
Macrophages are major targets of human immunodeficiency virus (HIV) and can act as long-term reservoirs of the virus. Chronic HIV-1 infection is associated with dysregulated inflammation. Recepteur d'origine nantais (RON) is expressed in tissue resident macrophages and functions to maintain inflammatory homeostasis. The present study aimed to compare the expression of RON on HIV-positive and -negative participants, and to investigate the mechanism by which HIV-1 influences the expression and function of RON in the JLTRG T cell line. The levels of RON and the RON ligand, macrophage-stimulating protein (MSP), in the peripheral blood of HIV-1-positive patients that were receiving $(n=22)$ or not receiving highly active anti-retroviral therapy (HAART) $(n=82)$ and 37 healthy control participants were determined by enzyme-linked immunosorbent assay. Expression of RON and MSP in the JLTRG T cell line was assessed by western blotting and the subcellular location was analyzed by fluorescence microscopy. JLTRG cells were co-cultured with a cell line that stably expresses HIV, H9/HTLV-IIIB, and alterations in the levels of RON and nuclear factor- $\mathrm{\kappa B}(\mathrm{NF}-\mathrm{\kappa B})$ in JLTRG cells were assessed by western blotting. The expression of RON and MSP were significantly different in the serum of HIV-1positive patients that were receiving HAART compared with
\end{abstract}

Correspondence to: Dr Tingting Feng, Department of Infectious Disease, The First Affiliated Hospital of Soochow University, 188 Shizi Street, Suzhou, Jiangsu 215006, P.R. China

E-mail: fengting3@163.com

Dr Hangping Yao, State Key Laboratory for Diagnosis and Treatment of Infectious Diseases, First Affiliated Hospital, Zhejiang University School of Medicine, 79 Qingchun Road, Hangzhou, Zhejiang 310003, P.R. China

E-mail: ttfeng251@suda.edu.cn

Key words: human immunodeficiency virus-1, Recepteur d'origine nantais receptor tyrosine kinase, nuclear factor- $\kappa \mathrm{B}$, macrophage-stimulating protein those not receiving HAART $(\mathrm{P}<0.05)$ and healthy control patients $(\mathrm{P}<0.01)$. RON was detected in JLTRG cells, and was shown to be downregulated by HIV-1 infection. HIV-1 infection of JLTRG cells also reduced NF- $\kappa \mathrm{B}$ phosphorylation. Thus, HIV-1 was shown to downregulate the expression and phosphorylation of RON by targeting the NF- $\mathrm{kB}$ pathway.

\section{Introduction}

Chronic human immunodeficiency virus (HIV) infection is characterized by dysregulated immune responses. In addition to $\mathrm{CD} 4^{+} \mathrm{T}$ cells, macrophages may be major reservoirs of HIV-1 infection (1-3), and HIV accessory proteins have been reported to influence macrophage immune activity (4).

Recepteur d'origine nantais (RON) also termed MST1R, is a receptor tyrosine kinase that is closely associated with c-Met expressed on tissue resident macrophages (5). RON has been reported to regulate macrophage function and inflammation (6). The RON ligand, macrophage-stimulating protein (MSP), is a member of the plasminogen-related growth factor family (7). MSP acts to inhibit the release of proinflammatory mediators, and enhances expression of genes associated with the resolution of inflammation. MSP stimulation of RON is reported to reduce the release of nitric oxide (NO), interleukin (IL)-12 and tumor necrosis factor (TNF)- $\alpha$ (8-11), and increase the expression of scavenger receptor A, IL-1R $\alpha$ and arginase (12). Deletion of RON impairs resistance to pathogens, and reduces autoimmune and pathogenic inflammatory conditions responses in animal models (13-15). As active transcription of HIV-1 is enhanced by inflammation, activation of RON likely acts to reduce HIV transcription. In addition, RON was recently reported to directly repress HIV-1 transcription by targeting RNA polymerase II (16). Overexpressing RON in monocytes reduced HIV-1 proviral transcription, and was reported to reduce the binding of nuclear factor- $\kappa \mathrm{B}(\mathrm{NF}-\kappa \mathrm{B})$ to the HIV-1 long terminal repeat (17).

Several HIV proteins have previously been reported to influence macrophage immune activity (4). HIV-encoded transactivator tat primarily acts to enhance HIV-1 transcription by increasing polymerase activity (18-20) and recruiting coactivators including to the HIV long terminal repeat (LTR) (21-23). 
However, tat was also reported to reduce cell-surface RON in HIV-infected monocytic cells by specifically tagging RON for proteasome degradation $(24,25)$. RON expression has been reported to be altered during chronic inflammation induced by HIV-1 infection of the brain $(16,17,24)$. However, the related mechanisms remain unclear.

The aim of this study was to examine the influence of HIV infection on the expression and function of RON in the peripheral blood of HIV-1-infected patients, and to investigate the role of RON in the HIV-1 infection of a T cell line. It was demonstrated that peripheral levels of RON were significantly higher in HIV-1-infected patients than in healthy control patients. In an in vitro model of HIV infection in the JLTRG T-cell line, RON expression and its phosphorylation were found to be downregulated by HIV-1 infection, which was accompanied by reduced NF- $\mathrm{NB}$ phosphorylation. Thus, HIV-1 downregulates the expression and phosphorylation of RON by targeting the NF- $\kappa \mathrm{B}$ pathway.

\section{Materials and methods}

Patients and participants. The cases at the First Affiliated Hospital of Zhejiang University (Hangzhou, China) and the First and Fifth Affiliated Hospitals of Suzhou University (Suzhou, China) between February 2011 and December 2013 were retrospectively reviewed. This study was approved by the Ethics Committee of the The First Affiliated Hospital of Soochow University (Suzhou, China). One hundred and four HIV-1-infected individuals and 37 healthy donors were enrolled in this study. Consent of the blood donors or their guardians was obtained in a manner consistent with the policies of the appropriate local institutions. HIV-1 infection was confirmed by a positive immunoblot and acquired immune deficiency syndrome (AIDS) was diagnosed based on the CDC classification (26). Of the $104 \mathrm{HIV}-1$ positive patients, 82 met WHO criteria (27) for highly active anti-retroviral therapy (HAART) initiation and received a stable antiretroviral regimen. In total, 22 were seropositive, but did not meet WHO criteria for HAART initiation. Healthy control participants $(n=37)$ were also recruited and were age-, gender-, and ethnicity-matched. A short medical history was obtained from all healthy control donors to ensure that they did not have an infectious disease in the past 3 months. Peripheral blood samples $(5 \mathrm{ml})$ from healthy, HIV-negative individuals and HIV-1-positive patients were drawn into a syringe containing EDTA and stored at $-80^{\circ} \mathrm{C}$.

Measurement of viral load and lymphocyte counts. Whole blood was treated with the red blood cell lysis buffer to lyse the red blood cells, and then centrifuged at 1,500 x $\mathrm{g}$ for $5 \mathrm{~min}$. The supernatant was discarded, and pellets were re-suspended in $200 \mu \mathrm{l}$ phosphate-buffered saline. The resultant cells were incubated with mouse fluorescein isothiocyanate (FITC)-conjugated CD4 monoclonal antibody (cat. no. 6603850; 1:10; Beckman Coulter, Brea, CA, USA) at room temperature for $1 \mathrm{~h}$, and analyzed using a flow cytometer.

Isolated lymphocytes from whole blood cells were stained with a PC5-conjugated CD4-directed monoclonal antibody (cat. no. A07752; 1:10; CD4-PC5; Beckman Coulter) and staining was analyzed on a FACS Calibur cell analyzer
(Becton Dickinson, USA). Flow cytometry data were analyzed using WINMDI software version 2.8 (The Scripps Institute, San Diego, CA, USA).

Measurement of RON and MSP in peripheral blood. The peripheral level of RON and MSP in blood samples was measured with a dual antibody switch enzyme-linked immunosorbent assay (ELISA) using the RON-directed mouse anti-Zt/G4 and 2F2 monoclonal antibodies (1:200; provided by Professor Wang, Texas Tech University Health Sciences Center, Amarillo, TX, USA) as described previously (28-31) and human MSP/MST1 $\alpha$ Chain MAb (Clone 45904), mouse IgG1 (R\&D Systems, Inc., Minneapolis, MN, USA).

Cell culture. The JLTRG cell line was a gift from the National Institutes of Health, (Baltimore, MD, USA), and the H9/HTLV-IIIB (human T cell line infected with HIV III) cell line was purchased from the American Type Culture Collection (Mannassas, VA, USA). The HeLa, L02, MRC, 293T, Huvee, Wish and Sup T1 cell lines were provided by First Affiliated Hospital, Zhejiang University School of Medicine (Hangzhou, China). All cell lines were cultured in RPMI-1640 (Invitrogen, Thermo Fisher Scientific, Inc., Waltham, MA, USA) supplemented with $10 \%$ fetal calf serum (Gibco, Thermo Fisher Scientific, Inc.), $100 \mathrm{U} / \mathrm{ml}$ penicillin, $100 \mathrm{mg} / \mathrm{ml}$ streptomycin and $0.2 \mathrm{M} \mathrm{L}$-glutamine at $37^{\circ} \mathrm{C}$ and $5 \% \mathrm{CO}_{2}$.

HIV infection of the JLTRG cell line. JLTRG cells $\left(1 \times 10^{6}\right)$ were cultured in a $10 \mathrm{~cm}$ culture dish, and co-cultured with H9/HTLV-IIIB cells to achieve a ratio of 10:1. After 24, 48, 72 and $96 \mathrm{~h}$, infection was assessed by fluorescence microscopy (Olympus IX81, Tokyo, Japan). RON, MSP and NF- $\kappa$ B content was assessed by western blotting, as described below.

Immunofluorescence. JLTRG cells were cultured on slides (Lab-Tek Chamber Slide system, Thermo Fisher Scientific, Inc.) and fixed with $4 \%$ paraformaldehyde at $4^{\circ} \mathrm{C}$ for $20 \mathrm{~min}$ and incubated with RON directed monoclonal antibody (2F2; 1:200; provided by Professor Wang) at room temperature for $1 \mathrm{~h}$. The cells were then further incubated with anti-mouse FITC-conjugated secondary antibody (cat. no. sc-3699; 1:10; Santa Cruz Biotechnology Inc., CA, USA) for $30 \mathrm{~min}$. Fluorescence was observed and photographed by a fluorescence microscope (Olympus IX81).

Immunoprecipitation and western blotting. Cells were incubated with lysis buffer (cat. no. 9803, Cell Signaling Technology Inc., Beverly, MA, USA) for $30 \mathrm{~min}$ at $4^{\circ} \mathrm{C}$. Insoluble material was then removed by centrifugation at $8,000 \mathrm{x} \mathrm{g}$ for $20 \mathrm{~min}$ at $4^{\circ} \mathrm{C}$, and the concentration of protein in each lysate was determined using a bicinchoninic protein assay kit (Pierce Biotechnology, Rockford, IL, USA) with bovine serum albumin (BSA; Sigma-Aldrich, St. Louis, MO, USA) as the standard. Immunoprecipitation and western immunoblotting was conducted as previously described (29). In brief, $20 \mu \mathrm{g}$ of protein lysate was mixed with $2 \mathrm{X}$ sodium dodecyl sulfate (SDS) loading buffer containing DTT and incubated at $100^{\circ} \mathrm{C}$ for $10 \mathrm{~min}$ before resolving by SDS-polyacrylamide gel electrophoresis. Proteins were transferred to a polyvinylidene difluoride membrane and blocked with $5 \%$ non-fat dry milk 
Table I. Clinical characteristics of enrolled participants.

\begin{tabular}{lcccc}
\hline Patient groups (n) & CD4 cells $\left(\right.$ count $\left./ \mathrm{mm}^{3}\right)$ & Viral load $\left(x 10^{7}\right.$ copies/ml) & RON (ng/ $\mu \mathrm{l})$ & $\mathrm{MSP}(\mathrm{ng} / \mu \mathrm{l})$ \\
\hline Untreated (22) & $182.41 \pm 91.81^{\mathrm{a}}$ & $0.0786 \pm 0.00296$ & $0.49 \pm 0.135^{\mathrm{a}, \mathrm{b}}$ & $0.97 \pm 0.29^{\mathrm{a}, \mathrm{c}}$ \\
Treated (82) & $213.47 \pm 138.06^{\mathrm{a}}$ & $0.0053 \pm 0.00244^{\mathrm{b}}$ & $0.77 \pm 0.202^{\mathrm{a}}$ & $0.64 \pm 0.39^{\mathrm{a}}$ \\
Healthy control (37) & $768.30 \pm 104.12$ & - & $0.26 \pm 0.036$ & $2.08 \pm 1.49$ \\
\hline
\end{tabular}

${ }^{\mathrm{a}} \mathrm{P}<0.01$, compared with healthy controls; ${ }^{\mathrm{b}} \mathrm{P}<0.05$ and ${ }^{\mathrm{c}} \mathrm{P}<0.01$ compared with the untreated group.

A Marker Hela L02 JLTRG MRC 293T Huvee Wish SupT1 PMBC

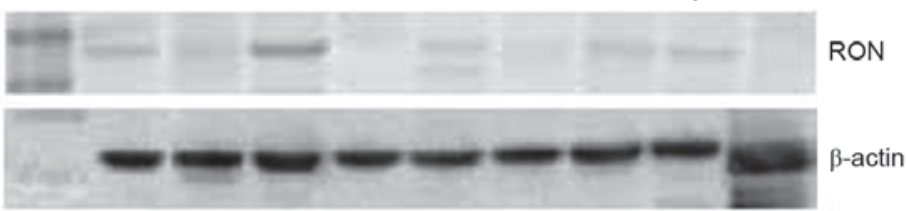

B

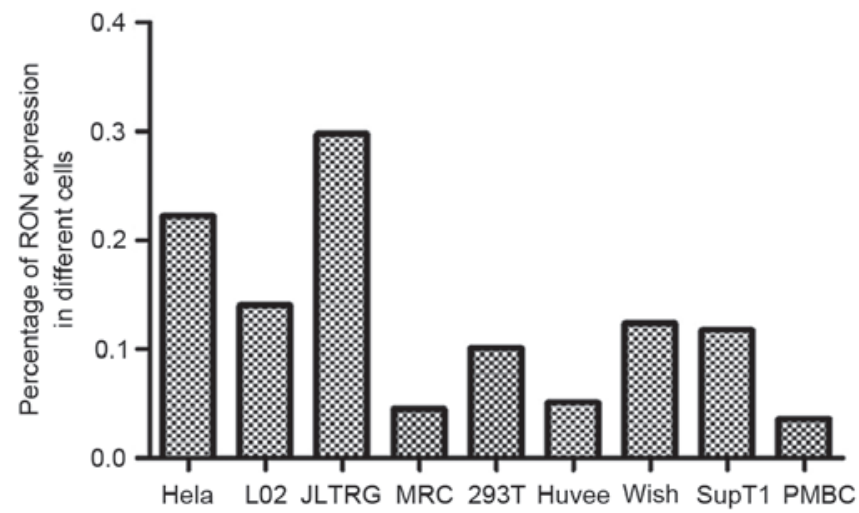

Figure 1. Expression of RON in cell lines and primary cells. RON is highly expressed in the JLTRG cells. (A) RON expression compared witht he housekeeping gene $\beta$-actin. (B) The relative expression of RON normalized to $\beta$-actin. RON, recepteur d'origine nantais.
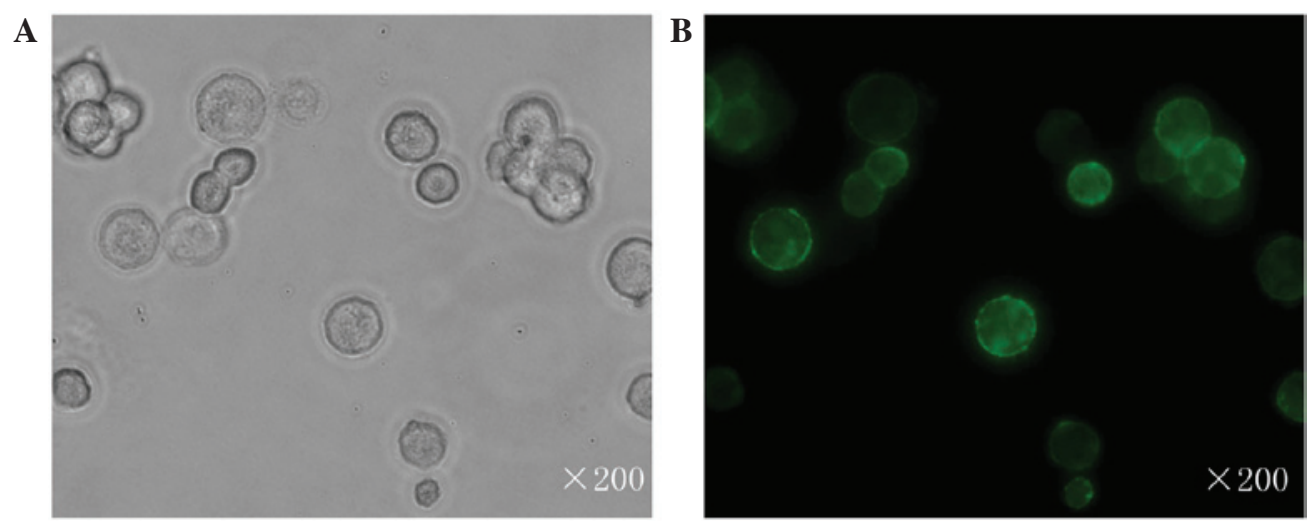

Figure 2. Location of RON in JLTRG cells. JLTRG cells were visualized with a fluorescein isothiocyanate-labeled antibody (2F2), directed towards the RON subunit (green). (A) Light microscopy, (B) fluorescence microscopy. These images are representative of at least 100 cells that were counted for each test condition $(\mathrm{n}=3)$ from two separate experiments. RON, recepteur d'origine nantais.

in phosphate-buffered saline (PBS) with $0.02 \% \mathrm{v} / \mathrm{v}$ Tween-20. The membrane was incubated with RON-directed monoclonal antibodies Zt/G4 and 2F2 and anti-p65 (cat. nos. ab16502; 1:1,000; Abcam, Cambridge, UK) or phospho-p65 polyclonal antibodies (cat. no ab86299; 1:2,000; Abcam), and antibody binding was detected with horseradish peroxidase
(HRP)-conjugated goat anti-rabbit IgG (cat. no. ab85760; 1:500; Abcam). For detection of $\beta$-actin, membranes were stripped with $100 \mathrm{mM}$ 2-ME, $62.5 \mathrm{mM}$ Tris- $\mathrm{HCl}$ (pH 6.7) and 2\% SDS for $30 \mathrm{~min}$ at $55^{\circ} \mathrm{C}$, and re-probed with $\beta$-actin directed mouse antibody for $1 \mathrm{~h}$ at $25^{\circ} \mathrm{C}$. Samples were washed four times with PBS and resuspended in $1 \mathrm{x}$ SDS buffer $[50 \mathrm{mM}$ Tris- $\mathrm{HCl}$ 


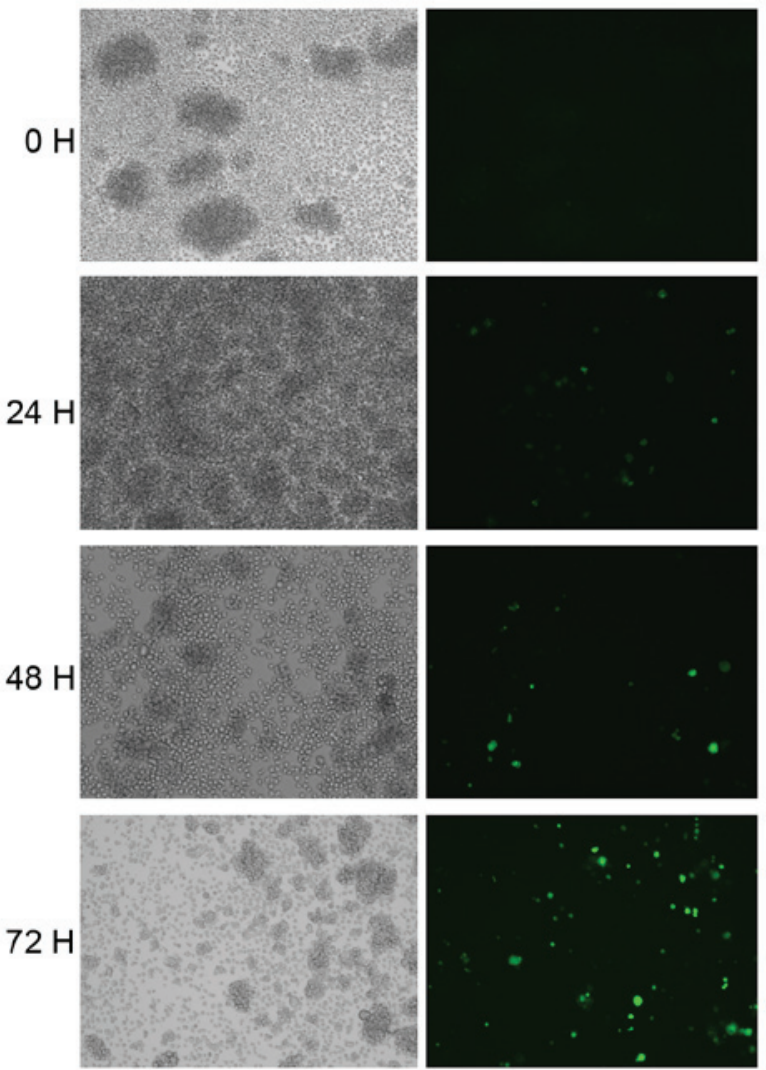

Figure 3. Infection of JLTRG cells. JLTRG cells $\left(1 \times 10^{6}\right)$ were co-cultured in a $10 \mathrm{~cm}$ culture dish with H9/HTLV-IIIB cells to achieve a ratio of 10:1. After $24,48,72$ and $96 \mathrm{~h}$ infection was assessed by immunofluorescence. These images are representative of at least 100 cells that were counted for each test condition ( $n=3)$ from two separate experiments. Magnification x 200.

(pH 6.8), 2\% SDS, $0.1 \%$ bromphenol blue, $10 \%$ glycerol, and $100 \mathrm{mM}$ DTT] Staining was detected with HRP-conjugated goat anti-mouse secondary antibody (cat. no. ab19195; 1:1,000; Abcam). Blots were scanned and analyzed using Image $\mathrm{J}$ version 1.45 software (National Institutes of Health, Bethesda, MD, USA) with protein band densities normalized to $\beta$-actin.

Statistical analysis. Quantitative data is expressed as the mean \pm standard deviation. Single-factor analysis of variance and linear correlation analysis was conducted using SPSS 17.0 statistical software (SPSS Inc., Chicago, IL, USA). P $<0.05$ was considered to indicate a statistically significant difference.

\section{Results}

RON and MSP levels in the serum of HIV-positive patients. In total, 104 HIV-1-infected individuals and 37 age- and gender-matched healthy control participants were enrolled. The mean age of the patients was $47.2 \pm 11.3$ (25-64) years. There were 62 male and 42 female HIV-1-infected patients; and 10 male and 18 female control participants. Expression levels of RON and MSP in the peripheral blood of HIV-1 positive patients receiving HAART $(n=22)$, or not $(n=82)$ and 37 healthy control participants were determined by ELISA. The level of RON in the peripheral blood was considerably higher in the plasma of HIV-1 positive patients undergoing HAART treatment $(0.77 \pm 0.202 \mathrm{ng} / \mu \mathrm{l})$ than in infected patients

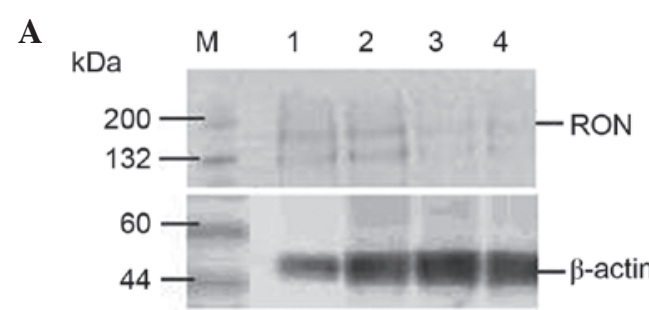

B

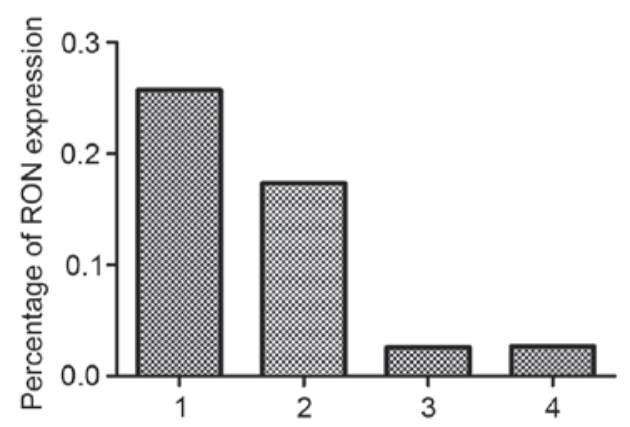

Figure 4. Expression of RON in JLTRG cells co-cultured with H9/HTLV-IIIB. (A) RON content of JLTRG cells cultured alone (1) or co-cultured with H9/HTLV-IIIB cells (10:1) for 24 (2), 48 (3) or $72 \mathrm{~h}$ (4) was assessed by western blot. (B) The relative expression of RON normalized to $\beta$-actin. RON, recepteur d'origine nantais.

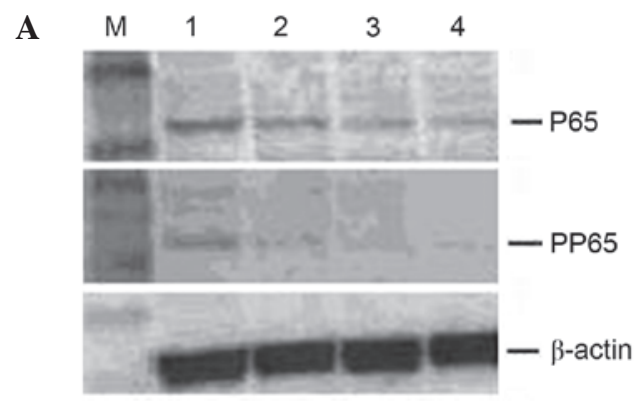

B
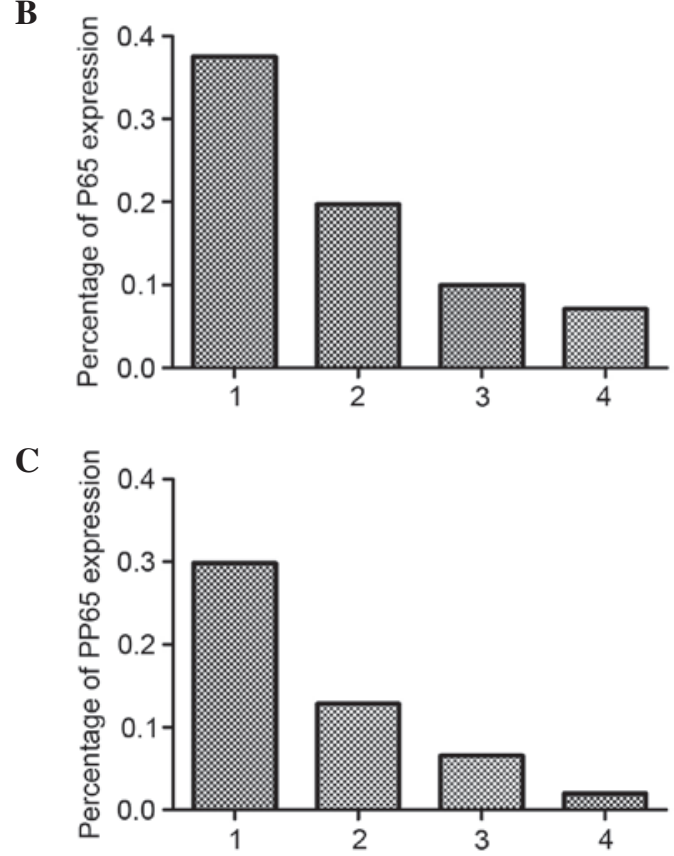

Figure 5. Expression of NF- $\mathrm{B}$ in JLTRG cells co-cultured with H9/HTLV-IIIB. (A) NF- $\kappa$ B content of JLTRG cells cultured alone (1) or co-cultured with H9/HTLV-IIIB cells (10:1) for 24 (2), 48 (3) or $72 \mathrm{~h}$ (4) was assessed by western blotting. Relative expression of (B) RON and (C) PP65 was normalized to $\beta$-actin. 
not undergoing HAART treatment $(0.49 \pm 0.135 \mathrm{ng} / \mu \mathrm{l})(\mathrm{P}<0.01)$. The levels in these groups were higher than the level in the healthy control group $(0.26 \pm 0.036 \mathrm{ng} / \mu 1, \mathrm{P}<0.05)$ (Table I).

The MSP level was considerably lower in the plasma of HIV-1 positive patients undergoing HAART treatment $(0.64 \pm 0.39 \mathrm{ng} / \mu \mathrm{l})$ than in infected patients not undergoing HAART treatment $(0.97 \pm 0.29 \mathrm{ng} / \mu \mathrm{l})(\mathrm{P}<0.05)$. The levels in these groups were lower than the levels in the healthy control group $(2.08 \pm 1.49 \mathrm{ng} / \mu 1, \mathrm{P}<0.05)$ (Table I).

Expression of RON and MSP in a T cell line. This study aimed to investigate the expression of RON and MSP in a range of human cell lines, and found RON to be strongly expressed in only JLTRG cells (Fig. 1). JLTRG cells are a Jurkat T cell-based cell line, which express CD4 and CXCR4, and have been stably transfected with an LTR-green fluorescence protein (GFP) construct in order to report HIV-1 infection. These cells can be infected with X4-tropic HIV-1 and in the presence of HIV-1 tat, expression of enhanced GFP acts as a quantitative marker of HIV-1 infection (32) The subcellular location of RON in JLTRG cells was assessed by immunofluourescent staining, and found it to be localized to the cell membrane (Fig. 2).

$H I V$ induces regulation of RON expression. To assess whether HIV-1 can affect the expression of RON and MSP JLTRG cells were infected by co-culture with H9/HTLV-IIIB cells (Fig. 3). The RON content of JLTRG cells cultured alone or co-cultured with H9/HTLV-IIIB cells was assessed by western blot analysis (Fig. 4). RON expression was demonstrated to be downregulated by HIV-1 infection in JLTRG cells. NF- $\kappa \mathrm{B}$ content of JLTRG cells cultured alone or co-cultured with H9/HTLV-IIIB cells (10:1) was assessed by western blot analysis. HIV-1 infection of JLTRG cells also reduced NF- $\mathrm{NB}$ phosphorylation (Fig. 5).

\section{Discussion}

Recently, several studies have suggested a direct interaction between RON and HIV-1 tat $(16,17,24)$. This study aimed to determine the circulating level of RON in patients with HIV-1 that were, or were not receiving HAART therapy. It was demonstrated that circulating levels of RON were significantly higher in HIV-1 infected patients than healthy control patients, and higher in patients that were receiving HAART therapy than those who were not. The converse was true of the RON ligand MSP. Circulating levels of MSP were significantly lower in HIV-1-infected patients compared with healthy control patients, and lower in patients that were receiving HAART therapy than those who were not.

HIV-1 tat was reported to downregulate RON, and RON expression has been reported to be altered during chronic inflammation induced by HIV-1 infection of the brain $(16,17,24,25)$. In a small study of brain tissues increased RON was detected in all seven HIV seronegative patients, but in six of nine patients with AIDS, reduced RON protein was detected (17). While depressed circulating RON was observed HIV-1 positive patients not receiving HAART compared with treated patients, in patients receiving HAART the RON level was significantly recovered. These findings support the consensus that HIV-1 tat specifically downregulates RON, likely enhancing the inflammatory environment under which HIV-1 replication thrives. The low peripheral level of RON of healthy controls likely reflects the lack of inflammation, and low level of inflammatory cells in the circulation, in comparison to the brain tissues (17).

This study aimed to investigate the mechanism by which HIV-1 downregulates RON. Thus the T-cell line, JLTRG, with high basal RON expression was investigated. HIV-1 infection of JLTRG cells reduced RON expression and its phosphorylation, which was accompanied by reduced NF- $\kappa \mathrm{B}$ phosphorylation. Thus, it was concluded that HIV-1 downregulates the expression and phosphorylation of RON by targeting the NF- $\kappa \mathrm{B}$ pathway in $\mathrm{T}$ cells. In addition, the downregulation of RON expression on the HIV-1 infected T cell surface may contribute to the increase in the circulating levels of RON in HIV-1-infected patients, probably via the release of the degraded RON on the T cell surface into the peripheral blood, which will be investigated in our future studies.

It was previously reported that HIV-1 tat mediates degradation of RON in HIV-1-infected monocytes (24), and that RON represses HIV-1 transcription by targeting RNA polymerase II processivity in a monocytic cell line (16). Overexpressing RON in monocytes/macrophages demonstrates that RON inhibits HIV-1 proviral transcription in part by decreasing the binding activity of NF- $\kappa \mathrm{B}$ to the HIV-1 LTR $(16,17)$. Consistent with the present findings in the JLTRG T cell line, RON expression decreased basal levels of $\mathrm{NF}-\kappa \mathrm{B}$ in a monocyte cell line, in addition to binding to the HIV provirus LTR and reducing efficient HIV-1 transcription (16).

These findings indicate that RON may influence the capacity of HIV to establish a latent reservoir in macrophages and $\mathrm{T}$ cell subsets, and influence the development of inflammatory microenvironments that favor HIV-1 replication. HIV-1 has thus evolved to specifically target RON, and may reduce RON activity by a range of mechanisms. This study reported that the downregulation of RON phosphorylation in a $\mathrm{HIV}-1$-infected $\mathrm{T}$ cell line is accompanied by reduced $\mathrm{NF}-\kappa \mathrm{B}$ phosphorylation. In conclusion the present study determined that HIV-1 infection modulated the RON function and thus provided a permissive environment for HIV-1 and other opportunistic microbes.

\section{Acknowledgements}

This study was supported by the Natural Science Youth Foundation of Jiangsu Province (Grant no. BK20130271) and the National Science and Technology Major Project (Grant no. 2012ZX10002004-008).

\section{References}

1. Meltzer MS, Nakamura M, Hansen BD, Turpin JA, Kalter DC and Gendelman HE: Macrophages as susceptible targets for HIV infection, persistent viral reservoirs in tissue and key immunoregulatory cells that control levels of virus replication and extent of disease. AIDS Res Hum Retroviruses 6: 967-971, 1990.

2. Balestra E, Perno CF, Aquaro S, Panti S, Bertoli A, Piacentini M, Forbici F, D'Arrigo R, Calió R and Garaci E: Macrophages: A crucial reservoir for human immunodeficiency virus in the body. J Biol Regul Homeost Agents 15: 272-276, 2001.

3. Kedzierska $\mathrm{K}$ and Crowe SM: The role of monocytes and macrophages in the pathogenesis of HIV-1 infection. Curr Med Chem 9: 1893-1903, 2002. 
4. Fantuzzi L, Belardelli F and Gessani S: Monocyte/macrophagederived CC chemokines and their modulation by HIV-1 and cytokines: A complex network of interactions influencing viral replication and AIDS pathogenesis. J Leukoc Biol 74: 719-725, 2003.

5. Leonis MA, Thobe MN and Waltz SE: Ron-receptor tyrosine kinase in tumorigenesis and metastasis. Future Oncol 3: 441-448, 2007.

6. Correll PH, Morrison AC and Lutz MA: Receptor tyrosine kinases and the regulation of macrophage activation. J Leukoc Biol 75: 731-737, 2004.

7. Wang MH, Julian FM, Breathnach R, Godowski PJ, Takehara T, Yoshikawa W, Hagiya M and Leonard EJ: Macrophage stimulating protein (MSP) binds to its receptor via the MSP beta chain J Biol Chem 272: 16999-17004, 1997.

8. Wang MH, Cox GW, Yoshimura T, Sheffler LA, Skeel A and Leonard EJ: Macrophage-stimulating protein inhibits induction of nitric oxide production by endotoxin- or cytokine-stimulated mouse macrophages. J Biol Chem 269: 14027-14031, 1994.

9. Chen YQ, Fisher JH and Wang MH: Activation of the RON receptor tyrosine kinase inhibits inducible nitric oxide synthase (iNOS) expression by murine peritoneal exudate macrophages: Phosphatidylinositol-3 kinase is required for RON-mediated inhibition of iNOS expression. J Immunol 161: 4950-4959, 1998.

10. Liu QP, Fruit K, Ward J and Correll PH: Negative regulation of macrophage activation in response to IFN-gamma and lipopolysaccharide by the STK/RON receptor tyrosine kinase. J Immunol 163: 6606-6613, 1999.

11. Morrison AC, Wilson CB, Ray $\mathrm{M}$ and Correll $\mathrm{PH}$ Macrophage-stimulating protein, the ligand for the stem cell-derived tyrosine kinase/RON receptor tyrosine kinase, inhibits IL-12 production by primary peritoneal macrophages stimulated with IFN-gamma and lipopolysaccharide. J Immunol 172: 1825-1832, 2004.

12. Morrison AC and Correll PH: Activation of the stem cell-derived tyrosine kinase/RON receptor tyrosine kinase by macrophage-stimulating protein results in the induction of arginase activity in murine peritoneal macrophages. J Immunol 168: 853-860, 2002.

13. Correll PH, Iwama A, Tondat S, Mayrhofer G, Suda T and Bernstein A: Deregulated inflammatory response in mice lacking the STK/RON receptor tyrosine kinase. Genes Funct 1: 69-83, 1997.

14. Leonis MA, Toney-Earley K, Degen SJ and Waltz SE: Deletion of the Ron receptor tyrosine kinase domain in mice provides protection from endotoxin-induced acute liver failure. Hepatology 36: 1053-1060, 2002.

15. Tsutsui S, Noorbakhsh F, Sullivan A, Henderson AJ, Warren K, Toney-Earley K, Waltz SE and Power C: RON-regulated innate immunity is protective in an animal model of multiple sclerosis Ann Neurol 57: 883-895, 2005

16. Klatt A, Zhang Z, Kalantari P, Hankey PA, Gilmour DS and Henderson AJ: The receptor tyrosine kinase RON represses HIV-1 transcription by targeting RNA polymerase II processivity. J Immunol 180: 1670-1677, 2008

17. Lee ES, Kalantari P, Tsutsui Section S, Klatt A, Holden J, Correll PH, Power Section C and Henderson AJ: RON receptor tyrosine kinase, a negative regulator of inflammation, inhibits HIV-1 transcription in monocytes/macrophages and is decreased in brain tissue from patients with AIDS. J Immunol 173 6864-6872, 2004.
18. Griffin GE, Leung K, Folks TM, Kunkel S and Nabel GJ: Activation of HIV gene expression during monocyte differentiation by induction of NF-kappa B. Nature 339: 70-73, 1989.

19. Harrich D, Garcia J, Wu F, Mitsuyasu R, Gonazalez J and Gaynor R: Role of SP1-binding domains in in vivo transcriptional regulation of the human immunodeficiency virus type 1 long terminal repeat. J Virol 63: 2585-2591, 1989.

20. Henderson AJ, Connor RI and Calame KL: C/EBP activators are required for HIV-1 replication and proviral induction in monocytic cell lines. Immunity 5: 91-101, 1996.

21. Agbottah E, Deng L, Dannenberg LO, Pumfery A and Kashanchi F: Effect of SWI/SNF chromatin remodeling complex on HIV-1 Tat activated transcription. Retrovirology 3: 48,2006

22. Mahmoudi T, Parra M, Vries RG, Kauder SE, Verrijzer CP, Ott $\mathrm{M}$ and Verdin E: The SWI/SNF chromatin-remodeling complex is a cofactor for Tat transactivation of the HIV promoter. J Biol Chem 281: 19960-19968, 2006.

23. Tréand $\mathrm{C}$, du Chéné I, Brès V, Kiernan R, Benarous R, Benkirane $M$ and Emiliani S: Requirement for SWI/SNF chromatin-remodeling complex in Tat-mediated activation of the HIV-1 promoter. Embo J 25: 1690-1699, 2006.

24. Kalantari P, Harandi OF, Hankey PA and Henderson AJ: HIV-1 Tat mediates degradation of RON receptor tyrosine kinase, a regulator of inflammation. J Immunol 181: 1548-1555, 2008.

25. Feng T, Shao X, Li J, et al: Human immunodeficiency virus (HIV)-1 Tat downregulates the phosphorylation of recepteur d'origine nantais (RON) receptor tyrosine kinase induced by macrophage-stimulating protein. African Journal of Biotechnology 10: 16610-16616, 2013.

26. Schneider E, Whitmore S, Glynn KM, Dominguez K, Mitsch A, McKenna MT and Centers for Disease Control and Prevention (CDC): Revised surveillance case definitions for HIV infection among adults, adolescents, and children aged $<18$ months and for HIV infection and AIDS among children aged 18 months to $<13$ years - United States, 2008. MMWR Recomm Rep 57: 1-12, 2008.

27. Hargreaves N, and Scano F: Guidelines for implementing collaborative TB and HIV programme activities, 2003.

28. Lu Y, Yao HP and Wang MH: Multiple variants of the RON receptor tyrosine kinase: Biochemical properties, tumorigenic activities and potential drug targets. Cancer Lett 257: 157-164, 2007.

29. Lu Y, Yao HP and Wang MH: Significance of the entire C-terminus in biological activities mediated by the RON receptor tyrosine kinase and its oncogenic variant RON160. J Exp Clin Cancer Res 27: 55, 2008.

30. Yao HP, Luo YL, Feng L, Cheng LF, Lu Y, Li W and Wang MH: Agonistic monoclonal antibodies potentiate tumorigenic and invasive activities of splicing variant of the RON receptor tyrosine kinase. Cancer Biol Ther 5: 1179-1186, 2006.

31. Guin S, Yao HP and Wang MH: RON receptor tyrosine kinase as a target for delivery of chemodrugs by antibody directed pathway for cancer cell cytotoxicity. Mol Pharm 7: 386-397, 2010.

32. Ochsenbauer-Jambor C, Jones J, Heil M, Zammit KP and Kutsch O: T-cell line for HIV drug screening using EGFP as a quantitative marker of HIV-1 replication. Biotechniques 40: 91-100, 2006. 